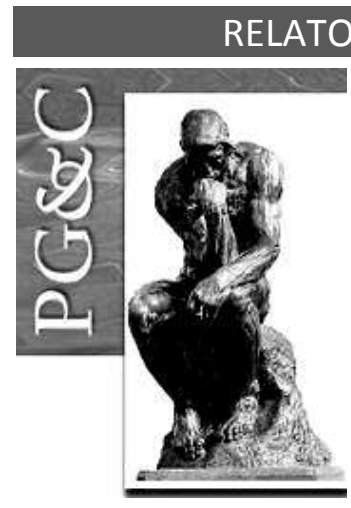

\title{
ANÁLISE DE RELAÇÕES INTERPESSOAIS NO JOGO DE EMPRESAS POR MEIO DA SOCIOMETRIA
}

\author{
Bruno Koenigkan Lopes \\ Graduado em Administração pela Universidade Federal Fluminense, Brasil. \\ E-mail: brunokoenigkan@id.uff.br \\ Letícia Duarte Andrade \\ Graduada em Administração pela Universidade Federal Fluminense, Brasil. \\ E-mail: leticiadandrade@yahoo.com.br \\ Sheila Serafim da Silva \\ Doutoranda em Administração pela Universidade de São Paulo, Brasil. \\ E-mail: sheila serafim@yahoo.com.br \\ Murilo Alvarenga Oliveira \\ Doutor em Administração pela Universidade de São Paulo, Brasil. Professor da \\ Universidade Federal Fluminense, Brasil. \\ E-mail: malvarenga@id.uff.br
}

\begin{abstract}
Resumo
O estudo das relações interpessoais e grupais nas organizações é importante. Esse estudo tem como objetivo analisar a dinâmica das relações interpessoais e intergrupais em um ambiente laboratorial. Trata-se de um ambiente que simula o processo de tomada de decisão de gestores por meio da técnica jogo de empresas, fundamentada na aprendizagem vivencial - aprender fazendo. Adotou-se uma abordagem qualitativa por meio da técnica Sociometria, coletando-se dados por meio de questionário aplicado a estudantes de graduação em Administração que participaram do ambiente laboratorial. 0 estudo analisa aspectos de alinhamento estratégico, distribuição de tarefas e responsabilidades e relacionamento entre eles. As empresas foram classificadas em grupo, equipe ou time e os participantes foram classificados em estrelas, pontes, panelas, pontes ou indivíduos isolados. Ao classificar as empresas e os participantes, os resultados evidenciaram a importância de se conhecer a estrutura das relações interpessoais e intergrupais dentro e fora do ambiente empresarial. A partir do conhecimento dessa classificação, as empresas podem investir nos pontos críticos para melhor o seu desempenho.
\end{abstract}

Palavras-chave: Laboratório de Gestão. Educação Gerencial. Indivíduo e Grupo.

\section{ANALYSIS OF INTERPERSONAL RELATIONS IN A BUSINESS GAME: COMBINING SOCIOMETRY AND ACTIVE METHODS IN ADMINISTRATION}

\begin{abstract}
This study of interpersonal and group relationships in organizations is important. This study aimed to analyze the dynamics of interpersonal and intergroup relations in a laboratory environment. It is an environment that simulates the decision-making process of managers through the game of business technique, based on experiential learning - learning by doing. A qualitative approach was adopted using the Sociometry technique, and data were collected through a questionnaire applied to undergraduate students in Administration who participated in the laboratory environment. The study analyzed aspects of strategic alignment, distribution of tasks and responsibilities and relationship between them. The companies were classified in group, team or team and the participants were classified in stars, bridges, pans, bridges or isolated individuals. When classifying companies and participants, the results discussed
\end{abstract}

Perspectivas em Gestão \& Conhecimento, João Pessoa, v. 7, n. 1, p. 153-169, jan./jun 2017. DOI: http://dx.doi.org/10.21714/2236-417X2017v7n1p153

http://periodicos.ufpb.br/ojs2/index.php/pgc. ISSN: 2236-417X. Publicação sob Licença (cc) EY-NC-ND 
the importance of knowing the structure of interpersonal and intergroup relationships within and outside the business environment. From the knowledge of this classification, companies can invest in critical points to better their performance.

Keywords: Laboratory of Management. Management Education. Individual and Group.

\section{INTRODUÇÃO}

As relações entre indivíduos e grupos vão além dos limites das organizações (CASTILLA et al., 2000). As relações entre indivíduos e grupos são importantes porque interferem no desempenho dos indivíduos, dos grupos e das organizações. A sociedade se organiza em rede, na qual as relações são dinâmicas e onde se estabelecem laços de diferentes pesos e forças entre os indivíduos (GRANOVETTER, 1973). Nessas relações, podem ocorrer diferentes variações entre competição, colaboração ou uma relação mista, a coopetição, na qual os indivíduos cooperam entre si para alcançar um objetivo comum (OLIVEIRA; LOPES, 2014). Para compreender as relações entre indivíduos e grupos no ambiente de trabalho, é importante conhecer a priori o contexto físico e moral das relações de trabalho (Casado, 2002), a natureza dos grupos e os aspectos que o envolvem.

A ausência de entendimento de como se dão as relações intergrupais e interpessoais nas organizações pode incorrer em prejuízos, como a falta de alinhamento dos propósitos do indivíduo aos da organização. Como consequência, pode-se ter um desempenho prejudicado no trabalho e nos resultados da organização, em virtude de insatisfação no trabalho, ausência de motivação ou interesse e prontidão. Da mesma forma, o entendimento de como se dão as relações interpessoais e intergrupais no ambiente de trabalho aumenta a compreensão dos fatos e da influência das relações interpessoais fora do ambiente de trabalho nas relações de trabalho, permite maior robustez nas estratégias que envolvem as relações de trabalho entre indivíduos e grupos e permite melhor alinhamento às necessidades e anseios dos seus colaboradores.

Uma empresa capaz de compreender a dinâmica das relações interpessoais e intergrupais e a posição dos seus membros nessa dinâmica, pode trabalhar melhor o desenvolvimento de competências nos seus colaboradores em prol de um bem comum. Destaca-se, então, a importância de se estudar e compreender como se dão as relações interpessoais e intergrupais no ambiente de trabalho e fora dele e como essas relações influenciam o ambiente organizacional. Assim, tem-se nesse estudo como questão de pesquisa: qual a dinâmica das relações interpessoais e intergrupais em um jogo de empresas?

Para isso, esse estudo buscará compreender a dinâmica das relações interpessoais e intergrupais em um ambiente laboratorial que faz uso de simulador organizacional e jogo de empresas. Nesse estudo, chama-se ambiente laboratorial o uso de um caso empresarial com diversos índices como o Produto Interno Bruto (PIB), a inflação, a sazonalidade, entre outros, que simulam um mercado real entre empresas (indústrias e atacadistas) do setor de eletrônicos. Nesse ambiente, dá-se o processo de tomada de decisão em que os participantes necessitam tomar decisões para a compra e venda de matéria-prima (caso das indústrias) e produtos acabados (caso das empresas atacadistas). Essa relação de compra e venda exige que os participantes interajam entre si dentro e fora das empresas. Nesse ambiente laboratorial, será usada a técnica educacional Jogo de Empresas e um Simulador Organizacional para simplificar a realidade de modo que os participantes possam aplicar teorias de gestão e vivenciar aspectos da realidade das empresas.

A análise das relações interpessoais e intergrupais ocorrerá em duas etapas: (1) classificação das empresas do ambiente laboratorial em grupo, equipe e time; (2) classificação

Perspectivas em Gestão \& Conhecimento, João Pessoa, v. 7, n. 1, p. 153-169, jan./jun. 2017. 
dos indivíduos que compõem as empresas em estrela, ponte, panela e isolado. Essas classificações estão fundamentadas na literatura (CASADO, 2002) e, a partir delas, pode-se compreender melhor as relações interpessoais e intergrupais que se formam nesse ambiente. Na etapa 1, será usado um questionário para coletar os dados que apoiarão a classificação das empresas. Na etapa 2 , será usada a técnica Sociometria, que permite visualizar a existência de grupos e subgrupos.

Espera-se com os resultados dessa pesquisa contribuir para reflexões acerca das relações interpessoais e intergrupais nas organizações e a influência das relações que ocorrem no ambiente externo no ambiente interno; pretende-se contribuir para reflexões acerca do uso de métodos ativos (jogo de empresas) na educação gerencial e apresentar uma possibilidade de aplicação das teorias de gestão para a produção de conhecimento e pesquisa na área; discutir como as organizações podem usar os resultados dessa pesquisa para aplicação prática, como exemplo, de que forma os indivíduos identificados como estrelas e pontes podem ajudar os isolados a desenvolverem suas habilidades de comunicação e ou promover maior interação com os demais.

\section{REVISÃO DE LITERATURA}

\subsection{Relações Interpessoais e Sociometria}

Quando os indivíduos estão inseridos em um ambiente organizacional, em convivência com outras pessoas, se desenvolvem tanto como indivíduo quanto profissionalmente. De acordo com Barabási (2003), não é certo ou até mesmo possível, que um dado ator, seja uma pessoa ou organização, viva independente e isolado de outros, ou seja, tudo e todos na sociedade interligados de alguma forma. Para compreender as interações que ocorrem entre esses dados atores, tanto dentro quanto fora da organização, é importante apresentar as definições a respeito das relações interpessoais.

Segundo Berscheid e Peplau (1983), as relações interpessoais são a junção entre duas ou mais pessoas e variam conforme o tempo de duração. São consideradas a base da sociedade e formadas de acordo com o contexto social no qual essa sociedade está inserida sob diversas influencias que nela atua. Dessa forma, podem ser reguladas por lei, costume ou acordo mútuo. As relações interpessoais têm a função de convocar as pessoas a terem reações recíprocas, ou seja, a terem um comportamento que vai de acordo com a atitude do outro indivíduo no qual ela está interagindo. $O$ efeito das reações que cada um tem sobre o outro, forma o comportamento do primeiro, e as características da relação entre eles vão determinar a sua devida qualidade. Isso determina a capacidade de um indivíduo em se adaptar a determinadas situações interpessoais de forma a alcançar os objetivos daquela relação, o que mantém o equilíbrio de poder e as trocas positivas na relação com as outras pessoas.

Moreno (1972) tinha interesse pela análise das relações interpessoais e com isso criou a técnica Sociometria, realizando estudos qualitativos e quantitativos das relações interindividuais com um grupo de prisioneiros para classificar aqueles que já teriam intensificado seu processo de reabilitação. Fez também diversos Sociogramas para descrever as relações que ocorrem nas escolas entre jovens durante suas escolhas de líderes para jogos, entre outros. $\mathrm{O}$ autor desenvolveu a Sociometria com o objetivo de relacionar as formas com que se davam as relações de afinidade, rejeições, indiferenças com fatores psicológicos e sociais observáveis (SARAVALI, 2005). Para Moreno (1972), a Sociometria é um instrumento que serve para construir a estrutura das relações intergrupais nos grupos sociais.

A técnica consiste expressamente em solicitar ao sujeito que escolha, no grupo ao qual pertence ou ao qual poderia pertencer, ou ainda os indivíduos aos quais gostaria de ter como companheiros. De acordo com Giacaglia e Penteado (2006), os dados coletados devem ser

Perspectivas em Gestão \& Conhecimento, João Pessoa, v. 7, n. 1, p. 153-169, jan./jun. 2017. 
reescritos para a construção de uma sociomatriz, que irá apresentar os nomes dos indivíduos da pesquisa em ordem alfabética, para enfim criar o gráfico da técnica chamado Sociograma. Constrói-se o Sociograma com os principais nomes colocados ao centro e os demais ao redor, com setas indicando as escolhas feitas. Por meio do Sociograma, pode-se visualizar as relações intergrupais, difíceis de perceber com a ausência dele, como observa Saravali (2005).

Borges (2010) define a Sociometria como estudos sobre redes que buscam compreender a dinâmica social, por vezes junto com a perspectiva econômica, podendo explicar o desenvolvimento organizacional e Inter organizacional em múltiplas escalas. Faz-se importante para a análise sociométrica observar o grau de proximidade dos indivíduos na rede, que corresponde à capacidade de um indivíduo em estar próximo de outras pessoas na interação, indicando um bom posicionamento na rede (LEMIEUX; OUIMET, 2008; OLIVEIRA; SOUZA; CASTRO, 2013). Assim, as interações interpessoais podem ser caracterizadas conforme sua capacidade de produzir os efeitos pessoais e sociais desejados, ou seja, nos termos da satisfação das necessidades individuais.

Para Blau (1977), tanto em nível individual quanto organizacional (micro e meso) as relações interpessoais que ocorrem em uma organização são importantes, já que o que acontece nessas relações dá forma e caracteriza as mudanças que ocorrerão dentro das empresas e no ambiente em que estão inseridas. Assim também as relações entre os indivíduos fora de uma organização são influenciadas pelas próprias relações e pela rede em que eles estão introduzidos.

É comum nas empresas relações de competição ou de colaboração. Isso ocorre porque é a partir dessas relações puras de competição e colaboração que surgem as relações intergrupais, em uma escala mais ampla, as organizações (BOISSEVAIN, 1968). É também a partir da competência social de cada indivíduo, que irá caracterizar positivamente ou não as relações que ocorrem e as organizações que se formam. Contudo, pode-se abordar outro tipo de relacionamento, o de coopetição, que só pode ser considerado quando se observam as relações entre indivíduos - relações interpessoais. Para desenvolver relacionamentos competitivos, sejam eles individuais ou organizacionais, os atores devem reunir interações, relações, atitudes, motivos, necessidades, objetivos e ações em comum.

As relações nas organizações formam grupos independentes e não relacionados entre si, sendo, portanto, relações intergrupais. Já as relações de indivíduos que pertencem a essas organizações se mostram uniformemente distribuídas, de modo que formam a estrutura mecânica das organizações (CASTILLA et al. 2000). As representações sociais regulam a relação entre os indivíduos e orientam o comportamento. As representações intervêm em processos tão variados como a difusão e a assimilação de conhecimento, a construção de identidades pessoais e sociais, o comportamento intra e intergrupal, as ações de resistência e de mudança social. Enquanto fenômenos cognitivos, as representações sociais são consideradas como o produto de uma atividade de apropriação da realidade exterior e, simultaneamente, como processo de elaboração psicológica e social da realidade.

Moscovici (1961) salienta que a especificidade da situação de cada grupo social contribui para a especificidade das suas representações, que contribui, por sua vez, para a diferenciação dos grupos sociais. Por um lado, as representações estruturam-se de acordo com as estratégias grupais e, por outro, as representações justificam os comportamentos grupais, isto é, as representações sociais têm uma função de justificação antecipada e/ou retrospectiva das interações sociais (JODELET, 1989). 


\subsubsection{Relações Intergrupais - O Indivíduo e o Grupo}

Para Moscovici (1994), com o passar do tempo, o trabalho em conjunto ganhou espaço nas organizações em detrimento do trabalho individual, pois perceberam que o trabalho coletivo contribui para o aumento da produtividade, eficiência, eficácia e a até mesmo da competitividade. Dessa forma, o trabalho em conjunto pode ser classificado em grupo, equipe e time.

O conceito de grupo está contido em equipe, que por sua vez está contido em time (CASADO, 2002). Um grupo é um conjunto de pessoas que compartilham valores, crenças e visões, de natureza relacional e de interação e alianças afetivas que dão unidade ao conjunto de pessoas. Uma equipe é um conjunto de pessoas que visam um objetivo comum, claramente definido, além da clareza na divisão de responsabilidades. Um time é um conjunto de pessoas com habilidades e potencialidades peculiares a serviço de um objetivo em comum, mas que compartilham valores, buscam resultados comuns e possuem alto grau de comprometimento. Katzenbach e Smith (1994) apresentaram algumas definições de tipos de grupos e equipes, conforme se pode observar no Quadro 1.

Quadro 1 - Tipos de Grupo e Equipe

\begin{tabular}{|c|l|}
\hline $\begin{array}{c}\text { Tipos de Grupo e } \\
\text { Equipe }\end{array}$ & \multicolumn{1}{|c|}{ Definições } \\
\hline Pseudo-equipe & $\begin{array}{l}\text { Grupo que tem o poder de escolher o trabalho a ser realizado, porém o } \\
\text { desempenho coletivo não é observado. As interações entre os integrantes } \\
\text { impedem o desempenho individual, chegando até a afetar o esforço coletivo que } \\
\text { não produz nenhum ganho. }\end{array}$ \\
\hline Grupo de Trabalho & $\begin{array}{l}\text { Os integrantes podem trocar informações. Porém, os produtos e } \\
\text { responsabilidades são individuais. Dessa forma, esses grupos não trabalham de } \\
\text { forma coletiva, pois seus integrantes não veem nenhum motivo para ser uma } \\
\text { equipe. }\end{array}$ \\
\hline Equipe Potencial & $\begin{array}{l}\text { Os integrantes estão inclinados a produzir algo em conjunto. Porém, necessitam } \\
\text { de maior explicação sobre as tarefas a serem feitas, como por exemplo: quais } \\
\text { seriam os objetivos e a finalidade. }\end{array}$ \\
\hline Equipe Real & $\begin{array}{l}\text { Os integrantes desse grupo trabalham com sinergia, confiança e estão atentos } \\
\text { aos resultados, pois sabem que estão trabalhando em prol de objetivos em } \\
\text { comum. }\end{array}$ \\
\hline Equipe de elevado & $\begin{array}{l}\text { Os integrantes do grupo têm uma preocupação quanto ao comprometimento do } \\
\text { crescimento pessoal e o desempenho de cada um dos membros, ou seja, querem } \\
\text { que todos obtenham sucesso. }\end{array}$ \\
\hline
\end{tabular}

Fonte: Katzenbach e Smith (1994).

A partir disso, pode-se dizer que a definição de equipe é mais completa que a de grupo, ou seja, o conceito de equipe é mais aprofundado. Dessa forma, pode-se observar que o conceito de time é mais abrangente que o dos outros - equipe e grupo (Figura 1). 
Figura 1 - Tipos de Trabalho

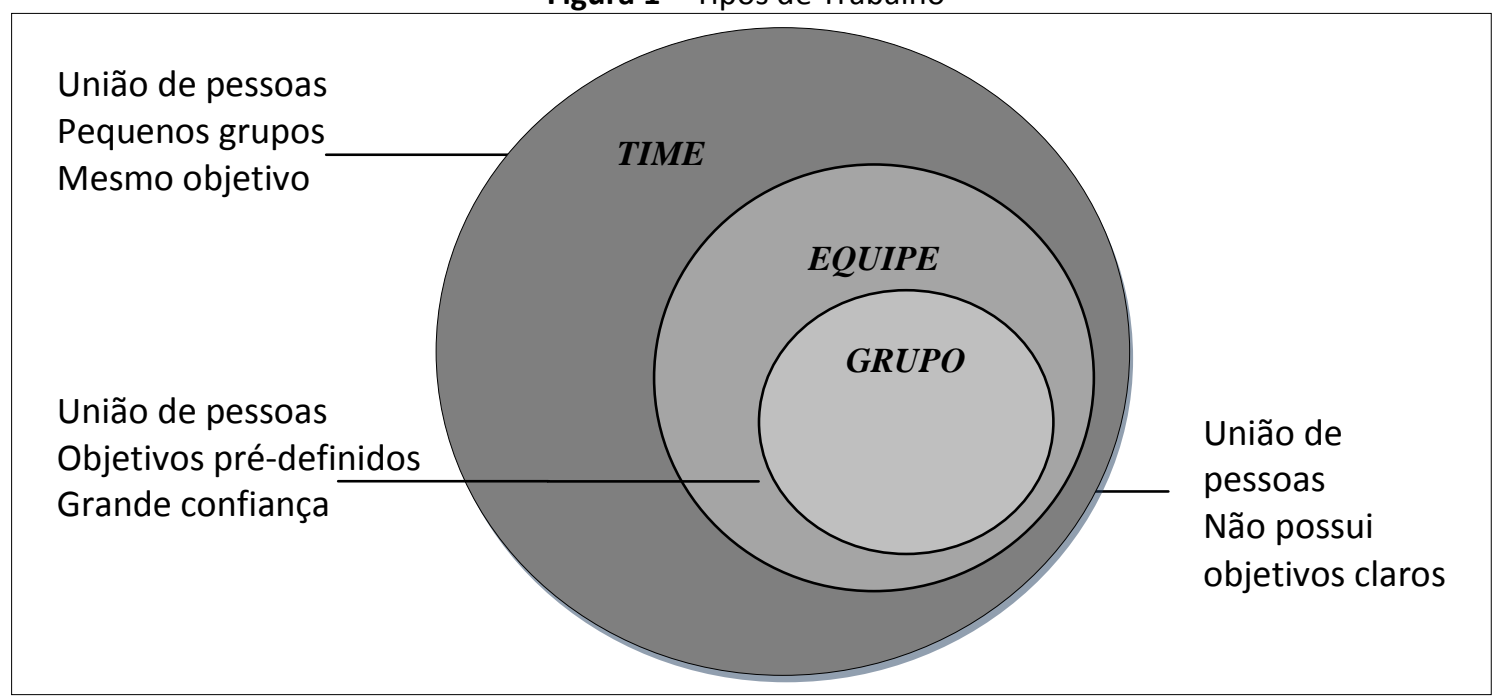

Fonte: Autoria própria com base em Casado (2002).

Casado (2002) classifica os padrões de interações interpessoais em: pontes, panelas, estrelas e indivíduos isolados. Indivíduos panelas são grupos de pessoas permanentes e que envolve o emocional dos integrantes. Indivíduos estrelas são pessoas envolvidas em um grupo com maior número de ligações com as outras pessoas, ou seja, são os mais procurados pelos integrantes dos grupos. Indivíduos pontes são pessoas que facilitam as ligações entre dois grupos ou panelas, porque pertencem a ambos e indivíduos isolados são aqueles que não fazem parte de nenhum grupo.

No nível interpessoal, Doise (1982) divide os tipos de relações em quatro, sendo dois destes níveis, o intra-individual e o posicional. A relação intra-individual, que considera o modo como os indivíduos percebem e se comportam e as suas práticas que desenvolverão as suas experiências e constituirão o objeto de análise. E a relação posicional, devido aos indivíduos terem diferentes práticas em relação ao ambiente, pela influência da posição social de determinado indivíduo, o que explica as diferentes formas de interação entre os indivíduos no ambiente. E também, porque neste nível, diz-se que as pessoas não podem ser substituídas por outras na interação, já que cada um apresenta uma característica diferente que irá contribuir para diversas formas de relações interpessoais no ambiente.

\subsection{Jogo de Empresas e Ambiente Laboratorial}

O jogo de empresas é um processo de gestão simulada em que os participantes fazem parte de um ambiente econômico no qual as decisões são tomadas. Os jogadores se organizam em grupos, analisam os resultados das jogadas anteriores, elaboram estratégias para as empresas e tomam decisões sobre as variáveis propostas, como por exemplo, o preço de um produto ou a quantidade a produzir (ROSAS; SAUAIA, 2006). De acordo com Babb et al. (1966), o jogo de empresas são exercícios de tomada de decisões gerenciais sequenciais, onde geralmente os resultados de outras equipes são afetados para satisfazer determinados objetivos em um ambiente de negócios e de mercado definido por um facilitador do jogo.

O jogo de empresas tem a finalidade de entender como os integrantes dos grupos processam os dados recebidos e assim tomam suas decisões em um local simulado que se parece com o ambiente empresarial real. 0 jogo recria um ambiente organizacional com materiais escritos parecidos com os utilizados em uma empresa real, tais como balanços patrimoniais, demonstrativos de caixa, demonstrativos de resultados, correspondências de 
trabalho, relatórios anuais e planos de gestão (SAUAIA, 1995). No jogo de empresas, as atividades realizadas por cada participante que se dividem em áreas funcionais, como marketing, produção, recursos humanos, operações e contabilidade, entre outras.

Os participantes assumem diferentes papéis gerenciais, estabelecidos previamente, definem metas e estratégias de sua organização. Dessa forma, pode ter o controle de suas ações e após cada rodada recebem os resultados produzidos por suas decisões que é gerado em um simulador, geralmente computadorizado. O trabalho simultâneo e competitivo dos vários grupos no jogo produz diversos resultados, soluções e problemas para o mesmo ambiente que são estabelecidos pelos seus próprios objetivos e metas. Não existem formas certas ou erradas ou fórmulas para se conduzir corretamente uma empresa no jogo de empresas. Os comportamentos e resultados suscitam discussões, dependendo dos conceitos, das teorias e das práticas realizadas durante o jogo. Além disso, os comentários dos resultados são imediatamente expostos aos participantes que podem rever ou confirmar suas práticas gerenciais.

O jogo de empresas é uma técnica que possui fundamentos da aprendizagem vivencial, sendo importante currículo dos cursos de Administração. Pfeiffer e Jones (1980, p. 21-22) sugerem que a "aprendizagem vivencial ocorre quando uma pessoa se envolve em uma determinada atividade, analisa-a criticamente extraindo algum insight útil e assim gera capacidade de aplicação de resultados". De acordo com Gentry e Schibrowsky (1990), o uso de um simulador pode proporcionar aos grupos o entendimento das estruturas de mercado, das variáveis que alteram os resultados das empresas e desenvolver habilidades de negociação com outros indivíduos, a fim de conseguir boas negociações independentes de ciclos de amizades. Dessa forma, o indivíduo pode associar as disciplinas cursadas no curso por meio do jogo de empresas. Isso contribui para uma visão mais sistêmica no decorrer do jogo de empresas e, consequentemente, melhores desempenhos dos estudantes no jogo.

O jogo de empresas pode promover a prática de teorias e conceitos e aproximar os participantes à realidade das organizações. A incerteza presente no simulador desafia os participantes ao limite de suas competências. Dessa forma, a conquista de resultados sustentáveis desafia o participante com um problema dinâmico, sujeito a mudanças não anunciadas. As múltiplas entradas e múltiplas saídas fazem do jogo um processo contínuo de criação, ou seja, no jogo, o grupo pode traçar inúmeras estratégias, e por muitas vezes aprender mais, colocando o que estudou em prática.

Uma característica do jogo de empresas, próprias para aprendizagem de participantes de cursos superiores, é especialmente a aprendizagem gerencial, ou seja, há uma possibilidade de cometer erros nas tomadas de decisões sem resultar em desperdícios no cenário real. Hilgard (1973) argumenta que na prática, nem sempre as decisões que os grupos tomam na sala de aula podem ser executadas nas empresas.

\section{PROCEDIMENTOS METODOLÓGICOS}

\subsection{Coleta e Análise dos Dados}

Esse estudo possui caráter qualitativo em virtude da natureza e tratamento dos dados. Trata-se de um estudo de caso, cujo objeto de estudo foi a disciplina Laboratório de Gestão Simulada II (LGSII), em uma Universidade Pública no Estado do Rio de Janeiro no curso de graduação em Administração.

Os dados foram coletados no ano de 2015 , com a aplicação de um questionário composto por 13 questões, cujo tempo médio de resposta foi de 20 minutos. Os questionários foram aplicados presencialmente e os participantes puderam esclarecer suas dúvidas quando necessário. O questionário consiste em um importante instrumento na obtenção de

Perspectivas em Gestão \& Conhecimento, João Pessoa, v. 7, n. 1, p. 153-169, jan./jun. 2017. 
informações. Essa escolha justifica-se pelo fato de se tratar de uma técnica de custo razoável, na qual se aplica as mesmas questões para todas as pessoas.

O questionário utilizado foi aplicado aos participantes da disciplina LGSII, que consiste em um ambiente laboratorial com uso de simulador organizacional e jogo de empresas. $O$ mesmo, foi dividido em duas partes. Na primeira, buscou-se identificar a classificação das empresas em grupo, equipe e time, levantando dados acerca da distribuição de tarefas e responsabilidades, do relacionamento interpessoal e do alinhamento estratégico. Na segunda parte, solicitou-se que o participante citasse, no máximo, três pessoas com as quais mais se relacionou no jogo de empresas, porém, solicitou-se também, que desconsiderassem os integrantes da mesma empresa, ou seja, não seria possível escolher os participantes da própria equipe de trabalho. $\mathrm{O}$ questionário foi reformulado após uma aplicação-teste com estudantes da mesma disciplina em um nível menos avançado no ano de 2014.

A composição da população desse estudo inclui todos os estudantes que cursaram a disciplina em caráter obrigatório na Instituição. Contudo, a amostra por conveniência trata-se de 11 (onze) estudantes que se encontravam matriculados na disciplina no período já citado e que se dispuseram responder ao questionário. Os estudantes possuem faixa-etária média de 20 anos e, no momento, estavam matriculados na disciplina do 50 período do curso de graduação em Administração. Tratam-se de estudantes do período noturno e, em sua maioria, trabalham ou fazem estágio.

A perspectiva dos estudantes acerca da formação dos grupos, equipes e times contribuiu para que os pesquisadores pudessem extrair significado das relações interpessoais e acerca da formação dos grupos. Para analisar o significado das relações interpessoais, as evocações (palavras, ideias e frases) foram analisadas por meio da técnica análise de conteúdo, tendo-se o cuidado de interpretar os resultados sem a influência dos pesquisadores. Para isso, os dados foram transcritos e categorizados nas dimensões grupo, equipe e time e depois confrontados com o Sociograma.

Utilizou-se o software UCINET para Windows 6.0 na versão 1.0 e o software NetDraw. A partir da análise, foram identificados os seguintes atores: estrelas ou conector central, pontes ou expansor de fronteiras, panelas e indivíduos isolados como apresentado na revisão de literatura desse estudo.

\subsection{O Ambiente Laboratorial}

A disciplina Laboratório de Gestão Simulada (LGS) tem início no terceiro período do curso de Administração como LGSI e continuidade no quinto período do curso como LGSII. Na disciplina LGSII, os estudantes são submetidos a um número maior de simulações no jogo de empresas, além de já estarem familiarizados com as regras econômicas do simulador e com a dinâmica da atividade. Cada jogo de empresas tem sua peculiaridade, no caso dessa atividade, os participantes foram distribuídos em equipes (empresas) e receberam as instruções acerca do funcionamento do jogo, as regras do simulador e a dinâmica do mercado. A atividade foi mediada pelo docente que acompanhou a sequência de simulações a cada período, sendo outro pesquisador o que aplicou o questionário.

Cabe mencionar uma distinção entre as disciplinas LGSI e LGSII. No primeiro nível, os estudantes são limitados às regras do simulador, enquanto no segundo nível, possuem liberdade para extrapolar a tomada de decisão, indo além das regras do simulador, e colocar em prática a criatividade e iniciativa no jogo de empresas. O fato do Simulador Grego Mix (SGM), usado na simulação, exigir a interação entre os participantes, e a decisão de uma equipe influenciar no desempenho das demais, estimula o relacionamento interpessoal, seja positiva ou negativamente, cabendo nesse estudo ser analisado e compreendido. 
O simulador é uma ferramenta importante na formação de gestores, pois além de simular a realidade, possibilita aos participantes a vivência de situações empresariais que podem ocorrer no contexto empresarial real. Assim, é possível experimentar de forma simplificada a tomada de decisão, podendo usar os conhecimentos adquiridos nas demais disciplinas. O simulador utilizado representa um mercado com três empresas, sendo elas atacados e indústrias. Tais empresas negociam três produtos: alfa, beta e ômega. Sendo assim, os estudantes que representam os atacados, precisam negociar com os diretores das indústrias, a fim de obter melhor preço de compra e definir as condições de pagamento destes Adotou-se uma abordagem qualitativa que, de maneira geral, não se preocupa em medir ou numerar o objeto de estudo (GODOY, 1995). A pesquisa buscou descrever as relações interpessoais, a formação de grupos e a classificação dos indivíduos em seus grupos, equipes e times na participação de um jogo de empresas.

Os participantes desse estudo constituem-se em atores de dois contextos diferentes: a) três grupos gestores de empresas do setor industrial que forneciam produtos de tecnologia aos demais grupos; b) dois grupos gestores de empresas do setor atacadista que compravam os produtos fornecidos pelas indústrias para ser vendido ao mercado final (varejo). A dinâmica do jogo de empresas exigia dos grupos uma interação para que a atividade fosse concluída.

As empresas eram constituídas por duplas, as quais desempenhavam papéis gerencias como presidente e diretores de áreas funcionais como Finanças, Produção ou Operações, Gestão de Pessoas e Marketing. O nome das empresas corresponde ao da atividade, porém os respondentes foram numerados para garantir a confidencialidade. Cabe ainda mencionar que o mediador da atividade representou uma empresa do setor industrial e que, apesar de não ter sido respondente, foi recorrentemente citado pelos inqueridos e, por isso, incluído na análise. A relação de empresas, seus respectivos setores e respondentes são apresentados no Quadro 2:

Quadro 2 - Distribuição dos participantes

\begin{tabular}{|l|l|l|}
\hline \multicolumn{1}{|c|}{ Setor } & \multicolumn{1}{|c|}{ Empresa } & \multicolumn{1}{c|}{ Respondente } \\
\hline \multirow{4}{*}{ Industria } & 1. Dohler & Respondente 1 e 5 \\
\cline { 2 - 3 } & 2. Cloak & Respondente 2 e 8 \\
\cline { 2 - 3 } & 3. MMVE & Respondente 3, 7 e 11 \\
\hline \multirow{2}{*}{ Atacado } & 4. Atach & Respondente 4 e 6 \\
\cline { 2 - 3 } & 5. Pear & Respondente 9 e 10 \\
\hline & Mediador (Empresa F) & Não respondente. \\
\hline
\end{tabular}

Fonte: Elaboração própria

\section{ANÁLISE E DISCUSSÃO DOS RESULTADOS}

\subsection{Análise por meio do Sociograma}

Nessa etapa, buscou-se analisar as relações entre os membros das empresas e suas conexões com outras empresas, a fim de classificar os indivíduos com base nas definições de Casado (2002): estrela, ponte, panela ou indivíduo isolado. Com os resultados coletados na segunda etapa da coleta de dados, foi possível elaborar o Sociograma indicando a estrutura das relações interpessoais dos participantes do jogo de empresas.

Com os resultados, pôde-se identificar os respondentes 8 e 9 como estrelas, pois interagiram com mais de duas empresas, sendo os mais citados pelos respondentes. Esse resultado deve-se ao fato dos indivíduos terem sido negociadores no jogo de empresas, terem orientado outros participantes ou segundo a definição de Casado (2002), por serem pessoas com maiores ligações com outros indivíduos, ou seja, pessoas mais procuradas pelos outros

Perspectivas em Gestão \& Conhecimento, João Pessoa, v. 7, n. 1, p. 153-169, jan./jun. 2017. 
integrantes dos grupos. Além desses, o mediador (Respondente 12) também pode se enquadrar nessa classificação, pois foi bastante procurado pelos outros participantes para sanar dúvidas e dar consultoria a respeito do jogo, ao mesmo tempo em que também faz negócios do seu atacado com as outras empresas. Outro resultado importante, é o de que todos os indivíduos considerados estrelas, não são pertencentes a mesma empresa, pois essa é uma característica de quem é estrela, ou seja, um indivíduo estrela é pertencente a Indústria, já o outro é pertencente ao Atacado, além do mediador.

Os indivíduos 3, 4, 6, 7 são facilitadores da comunicação entre os participantes e pertencem a dois grupos ou mais, sendo classificados como pontes. Porém, entre esses indivíduos citados, destaca-se os indivíduos 3 e 6 , pois se relacionaram com empresas de setor diferente, sendo considerados como indivíduos negociadores, aqueles que facilitam as ligações entre dois grupos ou panelas, porque pertencem a ambos, corroborando com a definição de Casado (2002).

Os indivíduos isolados, nesse caso, identificados como 1, 2, 5, 10, 11, são aqueles que não fazem parte de nenhum grupo, além da empresa a qual pertencem, pois estes, não foram indicados por nenhum respondente entre suas três opções de escolha. Os respondentes 1 e 5 pertencem a mesma empresa, já os demais, casos dos indivíduos 2, 10 e 11, cada um é pertencente a uma empresa diferente. Destaca-se que a Atach, é a única empresa que não possui indivíduos isolados na representação das relações interpessoais no Sociograma.

Fundamentado nas definições de Casado (2002), foi possível identificar os indivíduos panelas, que são grupos de pessoas permanentes e que envolve o emocional dos integrantes, sendo os casos das empresas MMVE e Atach que são grupos de trabalho em si, pois possuem indicações reciprocas, ou seja, cada uma votou na outra. Já no caso da empresa Dohler, ambos os integrantes indicaram as empresas Cloak e Pear, porém, não foram indicados reciprocamente, portanto, não se trata de uma panela. A quantidade de panelas justifica-se pelo baixo número de participantes por grupo que os membros da empresa podem ser escolhidos, formando-se assim, panelas.

Além disso, destaca-se que a Indústria Pear foi a que mais se relacionou com o mediador, já a que menos interagiu, foi a empresa Atach, pois não indicou o mediador entre as suas escolhas, como se pode observar no Sociograma. Dessa forma, pode-se inferir que a Indústria se relacionou mais com o mediador do que o atacado Atach. Já no caso da indústria Cloak, foi o indivíduo isolado 2 que mais se relacionou com o mediador, já no caso da indústria Dohler, ambos indivíduos isolados se relacionaram com o mediador, casos dos indivíduos 1 e 5. Já na empresa (Industria) com o maior número de diretores, a MMVE, todos citaram o mediador, casos dos indivíduos 3, 7, 11.

Com isso, pode-se inferir, que o mediador, respondente 12, é considerado uma ponte, pois, ele se relaciona com diferentes empresas, o que é natural pela dinâmica do jogo de empresas e proposta do simulador. Sendo assim, é classificado como estrela e ponte entre os próprios indivíduos. Pode-se dizer que há uma forte associação entre as empresas Cloak e Pear. Isso pode indicar que a Cloak tinha um relacionamento intenso com as empresas do setor distinto (indústria), ou seja, pode-se dizer que houve negociação.

A estrutura das relações interpessoais pode ser observada na Figura 2: 
Figura 2 - Sociograma das Relações Interpessoais

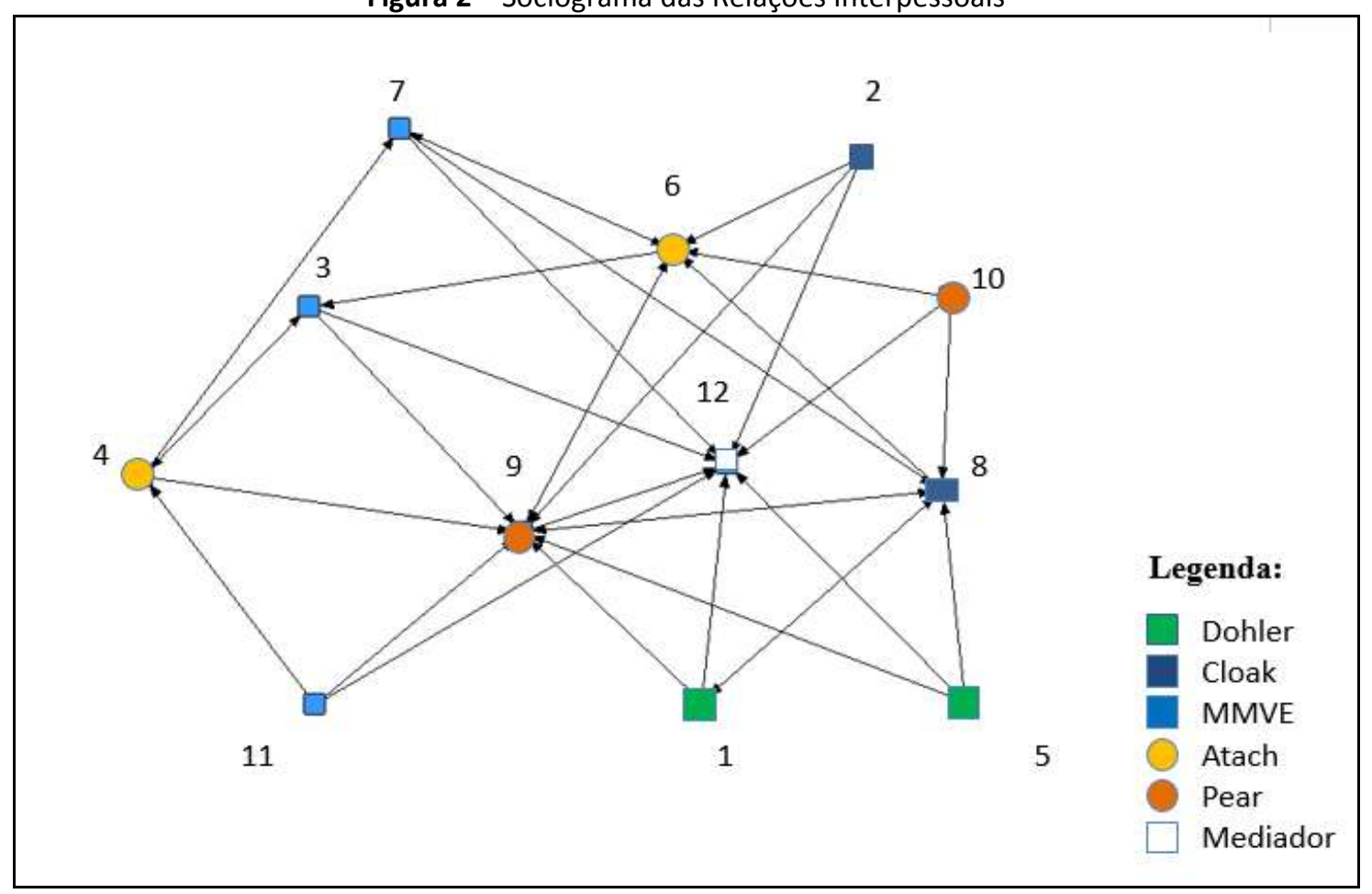

Fonte: Software UCINET

A partir da análise dos resultados e da classificação de Moscovici (1994) quanto a grupo, equipe e time, buscou-se enquadrar as empresas. Essa análise considerou a presença e alinhamento de objetivos da empresa por parte dos membros, a confiança mútua, o alinhamento estratégico e a relação entre eles.

Assim, pôde-se notar que a empresa Dohler, é um grupo, visto que não possuem objetivos alinhados, porém interagem entre si no cumprimento das tarefas em busca de resultado. Pôde-se observar que nas empresas Cloak e MMVE os integrantes possuem relação de confiança uns nos outros, objetivos pré-definidos, assumem riscos e estimulam a divergência de opiniões, resultando em debates, onde o consenso tem prioridade, podendo serem classificadas como equipe. A análise do discurso dos integrantes das empresas Pear e Atach pôde-se identificar que possuem uma relação de união e que são engajados, sendo possível identificar uma missão comum e assim, sendo elas classificadas como time, fundamentando-se nas definições de Moscovici (1994).

A partir da análise do Sociograma, pode-se notar que os indivíduos considerados estrela, caso do indivíduo 8, é pertencente a uma equipe, enquanto o indivíduo 9 está inserido em um time, ou seja, esses indivíduos, são os mais requisitados perante aos outros diretores das empresas, porém, esse fator não é preponderante para a classificação das empresas em grupos, equipes ou times, pois é um fator individual, já a sinergia entre os membros da empresa é considerada um essencial para essa análise.

\subsection{Análise dos Tipos de Equipe}

Dividiu-se a análise dos tipos de equipe em distribuição de tarefas e responsabilidades, relacionamento interpessoal e alinhamento estratégico. 


\subsubsection{Distribuição de Tarefas e Responsabilidades}

No que tange à distribuição de tarefas e responsabilidades, os resultados são apresentados na sequência: (1) na empresa Dohler, as atividades são realizadas em conjunto, tais como negociação, planejamento, marketing, apesar de um integrante ser mais responsável pela venda de produtos por ter maior facilidade de comunicação. Os relatórios são analisados em conjunto, assim como as decisões em cada etapa das simulações; (2) na empresa Cloak, as tarefas são realizadas em conjunto, tais como produção e a negociação dos produtos; (3) na MMVE, as responsabilidades são bem definidas, já que um é responsável por negociar os produtos, preços e prazos, enquanto outro responsabiliza-se pela parte financeira e produção, onde ajusta e organiza os resultados em uma planilha para trabalhar os dados, ao passo que outro integrante participa das duas áreas e desenvolve projetos com foco na vantagem competitiva. As trocas de informações e a organização para analisar os resultados são realizadas basicamente da mesma forma pelas três empresas citadas, seja em sala de aula, por meio de redes sociais ou correio eletrônico.

No caso das empresas do setor atacadista, descreve-se a seguir a distribuição de tarefas e responsabilidades das empresas: (4) na empresa Pear, busca-se dividir as tarefas e responsabilidades em duas áreas: estratégica e negociação, enquanto um integrante aprofunda a análise de dados passados, o outro foca em estratégias para a melhor negociação. As atividades são realizadas dentro e fora da sala de aula, buscando maior sinergia e facilidade na comunicação; (5) na empresa Atach, a divisão de tarefas e responsabilidades é dividida de forma semelhante, sendo um mais responsável pela estratégia e decisão e outro pela negociação. As decisões são tomadas também durante a aula e extraclasse.

\subsubsection{Relacionamento Interpessoal}

No que diz respeito ao relacionamento interpessoal, são descritos na sequência os resultados: (1) na empresa Dohler, identificou-se que existe os integrantes possuem amizade extraclasse. Na atividade do jogo de empresas, possuem um ambiente de confiança mútua e respeito. Entre empresas, a Dohler possui bom relacionamento, apesar de alguns conflitos com integrantes de outras empresas, que são resolvidos com profissionalismo e confiança mútua; (2) na empresa Cloak, os integrantes compartilham as mesmas opiniões e também possuem amizade fora do jogo de empresas. De acordo com os relatos, eles se encontram com frequência e o bom relacionamento é o principal motivador para a atividade. Entre empresas, não há conflitos, mas parcerias e acordos formais de colaboração; (3) na empresa MMVE, pôde-se perceber que há um bom relacionamento entre os membros, que facilita a tomada de decisão e incentiva a busca por melhores resultados, além de contribuir para maior comprometimento de todos os participantes. Nesse caso, possuem confiança mútua e relação de parceria entre si. Entre empresas, possuem atitude profissional e relação de profissionalismo.

Sobre as tarefas e responsabilidades nas empresas atacadistas, os resultados são descritos na sequência: (4) na Pear, os integrantes possuem bom relacionamento, sendo este também fora da sala de aula. As ideias são convergentes e compartilhadas. Entre empresas, há ausência de conflitos e a amizade com integrantes de outras empresas facilitam as negociações; (5) na empresa Atach, os integrantes relataram ausência de conflitos, alto comprometimento com as atividades e confiança mútua. 


\subsubsection{Alinhamento Estratégico}

No que diz respeito ao alinhamento estratégico das indústrias, os resultados são descritos na sequência: (1) na empresa Dohler foram citados a liderança de mercado e o foco em diferenciação como objetivos, sendo possível identificar divergências na declaração dos integrantes e a ausência de claro e compartilhado; (2) na empresa Cloak, há divergências quanto à visão da empresa, tendo alguns à direcionado para a área mercadológica e outros para a financeira e estratégica. Apesar dos integrantes compartilharem a ideia de maximização do lucro, identificou-se que não possuem objetivos claros; (3) na empresa MMVE, o alinhamento estratégico é divergente, pois enquanto um integrante declarou se tornar uma empresa global por meio de exportação, o outro declarou pretender buscar um crescimento interno por meio de parceria com os concorrentes.

No que tange ao alinhamento estratégico das empresas atacadistas, os resultados são descritos na sequência: (1) na empresa Pear, pôde-se identificar que há alinhamento estratégico e os integrantes mostraram-se motivados para alcançar o mesmo objetivo; (2) na empresa Atach, os integrantes relataram a estratégia compartilhada de aumentar o lucro por meio da redução de custos e despesas, visando a maior taxa de retorno (TIR), além de distribuir dividendos e reajuste de salários.

Os casos apresentados indicam que a empresa Dohler, por sua ausência de objetivo compartilhado e divergência de visões, aproxima-se mais de um grupo, pelo fato dos integrantes não trabalharem de forma coletiva, apoiando-se na literatura de Katzenbach e Smith (1994). Por outro lado, os casos das empresas Cloak e MMVE apresentam características de equipe, como defende Casado (2002), pela presença de objetivos pré-definidos e confiança mútua. Os casos das empresas, Pear e Atach, possuem características de um time, conforme a literatura de Casado (2002). Ambas as empresas apresentaram características de engajamento, objetivos claros e compartilhados entre os integrantes e comprometimento para a realização da tarefa.

O Quadro 3 resume a análise por empresa em termos de distribuição de tarefas e responsabilidades, relacionamento e alinhamento estratégico e a classificação das empresas em grupo, equipe e time, conforme a literatura apresentada.

Quadro 3 - Formação e Características das empresas

\begin{tabular}{|c|c|c|c|c|}
\hline Empresa & $\begin{array}{c}\text { Tarefas e } \\
\text { Responsabilidades }\end{array}$ & $\begin{array}{c}\text { Relacionamento Interno } \\
\text { (entre integrantes) }\end{array}$ & $\begin{array}{l}\text { Alinhamento } \\
\text { Estratégico }\end{array}$ & $\begin{array}{l}\text { Tipo de } \\
\text { (Equipes) }\end{array}$ \\
\hline 1. Dohler & $\begin{array}{l}\text { - Não há distribuição } \\
\text { clara de tarefas e } \\
\text { responsabilidades. }\end{array}$ & $\begin{array}{l}\text { - Amizade } \\
\text { extraclasse; } \\
\text { - } \text { Relação de confiança } \\
\text { mútua e respeito. } \\
\text { - Interagem entre si } \\
\text { para cumprimento } \\
\text { das tarefas. }\end{array}$ & $\begin{array}{l}\text { - Não possuem } \\
\text { objetivo pré- } \\
\text { definido; } \\
\text { - Possuem visões } \\
\text { semelhantes. }\end{array}$ & - Grupo \\
\hline 2. Cloak & 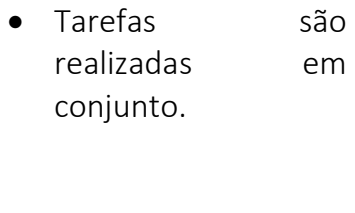 & $\begin{array}{l}\text { - Amizade } \\
\text { extraclasse; } \\
\text { - Compartilham as } \\
\text { mesmas ideias; } \\
\text { - Confiança mútua. }\end{array}$ & $\begin{array}{l}\text { - Opiniões } \\
\text { divergentes. } \\
\text { - Se unem para } \\
\text { alcançar os mesmos } \\
\text { objetivos. }\end{array}$ & - Equipe \\
\hline
\end{tabular}

Perspectivas em Gestão \& Conhecimento, João Pessoa, v. 7, n. 1, p. 153-169, jan./jun. 2017. 
Quadro 3 - Formação e Características das empresas - (Continuação)

\begin{tabular}{|c|c|c|c|c|}
\hline 3. MMVE & $\begin{array}{l}\text { - Tarefas e } \\
\text { responsabilidades } \\
\text { são bem definidas. }\end{array}$ & $\begin{array}{l}\text { - Bom } \\
\text { relacionamento; } \\
\text { - Comprometimento } \\
\text { de todos os } \\
\text { integrantes; } \\
\text { - Confiança mútua e } \\
\text { relação de parceria. }\end{array}$ & $\begin{array}{l}\text { - Possuem objetivos } \\
\text { pré-definidos; } \\
\text { - Assumem riscos. }\end{array}$ & $\bullet$ \\
\hline 4. Pear & $\begin{array}{l}\text { - Partilham as tarefas } \\
\text { e responsabilidades. }\end{array}$ & $\begin{array}{l}\text { - Amizade } \\
\text { extraclasse; } \\
\text { - Pensamentos e } \\
\text { ideias convergentes; } \\
\text { - Possuem as mesmas } \\
\text { opiniões. }\end{array}$ & $\begin{array}{l}\text { - Possuem objetivo } \\
\text { claramente definido; } \\
\text { - Engajados em } \\
\text { alcançar uma } \\
\text { missão. }\end{array}$ & \\
\hline 5. Atach & $\begin{array}{l}\text { - Tarefas exercidas } \\
\text { em conjunto, apesar } \\
\text { das } \\
\text { responsabilidades } \\
\text { bem definidas. }\end{array}$ & $\begin{array}{l}\text { - Amizade } \\
\text { extraclasse; } \\
\text { - São comprometidos } \\
\text { e se preocupam com } \\
\text { o desempenho; } \\
\text { - Possuem confiança } \\
\text { mútua e respeitam a } \\
\text { opinião dos demais. }\end{array}$ & $\begin{array}{l}\text { - Possuem objetivo } \\
\text { claro } \\
\text { compartilhado; } \\
\text { - Unidos para o } \\
\text { alcance da mesma } \\
\text { missão. }\end{array}$ & - Time \\
\hline
\end{tabular}

Fonte: Elaboração própria

\section{CONSIDERAÇÕES FINAIS}

Esse estudo teve como objetivo analisar a dinâmica das relações interpessoais em um jogo de empresas, utilizando-se da técnica Sociometria para classificar as empresas em grupo, equipe e time e os indivíduos em panelas, pontes, estrelas e isolados. A partir dos achados, pode-se afirmar que os objetivos da presente pesquisa foram atingidos. Concluiu-se que 0 Sociograma é uma técnica importante para a análise de grupos e indivíduos, nesse caso, empresas e participantes de um jogo de empresas. O estudo e a visualização das relações interpessoais por meio de um gráfico podem ajudar na elaboração de estratégias competitivas ou até mesmo no entendimento do papel de cada indivíduo no jogo de empresas, a fim de obter vantagem diante dos concorrentes.

A contribuição deste estudo está na compreensão das relações intergrupais no contexto do jogo de empresas e suas possibilidades e na importância que este estudo proporciona para a produção científica e formação de novos administradores que irão atuar nas organizações. Conclui-se que a formação de grupos, equipes e times se dá com base em aspectos coletivos, como confiança mútua, objetivos pré-definidos e compartilhados ou não, amizades entre outros.

O esforço empreendido para a elaboração do presente estudo é um passo preliminar para o uso de Sociometria para análise de relações interpessoais no contexto de um jogo de empresas, pois foram encontrados poucos estudos (SILVA; LOPES; ANDRADE, 2014) que associam ambos os temas. A análise das relações interpessoais no contexto do jogo de empresas foi interessante devido a interdisciplinaridade, o que permitiu aos graduandos superar seus próprios desafios em um ambiente sob pressão, dada a competição existente.

A análise das relações intergrupais foi importante, pois essa é de extrema importância para os gestores das organizações. Compreender como as relações entre os indivíduos e grupos estão estruturadas pode contribuir para a elaboração de estratégias e o processo de tomada de decisão. Em concordância com a proposta de Boissevain (1968), pode-se a partir 
dessa análise identificar a competência social de cada indivíduo, o que irá caracterizar positiva ou negativamente as relações que ocorrem e como as organizações se formam.

A partir da aplicação da Sociometria, foi possível classificar os indivíduos em panelas, estrelas, pontes e isolados, sendo possível identificar as relações entre eles. Conclui-se que as relações entre os indivíduos dentro e fora das organizações são influenciadas pelas redes de relacionamento em que estão inseridos, em concordância com a proposta de Blau (1977) de que tanto em nível individual quanto organizacional as relações interpessoais são essenciais e dão forma e caracterizam as mudanças que ocorrem nas empresas e no ambiente em que estão inseridas.

O estudo teve algumas limitações que devem ser explicitas aqui. Em primeiro lugar, destaca-se o número reduzido de participantes por empresas no jogo e na atividade como um todo, o que limitou a elaboração do Sociograma e uma análise mais ampla dos resultados. Pode ser que se houvessem mais respondentes, participantes no jogo de empresas, os conflitos, as negociações e a competição seria maior, influenciando na estrutura das relações interpessoais. Em segundo lugar, foi o fato de não se ter investigado os formulários de decisão das equipes, não sendo possível inferir qual a relação de compra e venda entre as empresas no jogo de empresas. Por fim, não foi usado escala para classificar o nível do relacionamento. A análise foi feita a partir de questões abertas em um questionário, sendo a pesquisa estritamente qualitativa. A amostra por conveniência também pode ser citada como uma limitação desse estudo.

Como perspectivas para estudos futuros, apresentamos que o estudo do Sociograma deve ser aplicado em uma turma de jogos de empresa onde as empresas tenham o maior número de indivíduos possíveis, para que uma maior quantidade de informação seja recolhida e consequentemente tabulada. A posse dos formulários de decisão também é uma sugestão, pois facilita a identificação de quem forneceu e de quem comprou, sendo assim, a tabulação dos dados e construção do Sociograma fica mais clara e fácil, consequentemente, melhora o entendimento.

\section{REFERÊNCIAS}

BABB, E. M.; LESLIE, M. A.; VAN SLYKE, M. D. The potential of business-gaming methods. Research, Oct. v. 39, n. 4, p.465-472, 1966.

BARABÁSI, A.L. Linked: how everything is connected to everything else and what it means for business, science and everyday life. New York: Plume, Penguin Group. 2003.

BERSCHEID, E.; PEPLAU, L. A. The emerging science of relationship. In H. H. KELLEY, E. BERSCHEID, A. CHRISTENSEN, J. H. HARVEY, T. L. HUSTON, G. LEVINGER (Orgs.), Close relationships. San Francisco: Freeman and Company, 1983.

BLAU, P. M. A macrosociological theory of social structure. The American Journal of Sociology. v. 83, n. 1, p. 26-54, 1977.

BOISSEVAIN, J. The place of non-groups in the social sciences. Man, v. 3, n. 4, 542 556, 1968.

BORGES, Z. Gestão e cooperação em redes. Revista de Administração de Empresas, v. 50, n. 3, p. 347-347, 2010.

CASADO, T. O papel da comunicação interpessoal. In: FLEURY, Maria Tereza Leme (Org.). As pessoas na organização. 1 ed.São Paulo: Gente, 2002, p. 271-282.

O indivíduo e o grupo: a chave para o desenvolvimento. In: FLEURY, Maria Tereza Leme (Org.). As pessoas na Organização. 1ed.São Paulo: Editora Gente, 2002, v. 1, p. 235-246.

Perspectivas em Gestão \& Conhecimento, João Pessoa, v. 7, n. 1, p. 153-169, jan./jun. 2017. 
CASTILLA, E. J.; HWANG, H.; GRANOVETTER, E.; GRANOVETTER, M. Social networks in silicon valley. The silicon valley edge. Stanford: Stanford University Press, p. 218-247, 2000.

DOISE, Willem. L'Explication en Psychologie Sociale. Paris: P.U.F., 1982.

GENTRY, J. W.; SCHIBROWSKY, J. A transaction cost analysis of experiential. Developments In Business Simulation \& Experiential Exercises. v. 17, 1990.

GIACAGLIA, L. R. A.; PENTEADO, W. M. A. Orientação educacional na prática: princípios, técnicas, instrumentos. São Paulo: Pioneira Thomson Learning, 2006.

GODOY, A. S. Introdução a pesquisa qualitativa e suas possibilidades. Revista de Administração de Empresas, v. 35, n. 2, p. 57-63, 1995.

GRANOVETTER, M. The strength of weak ties. American Journal of Sociology. University of Chicago Press, v. 78, n. 6, 1973.

HILGARD, E. R. Teorias da aprendizagem. São Paulo: Epu-EduSP, 1973.

JODELET, D. Les Représentations sociales: un domaine en expantion. Les représentations Sociales. Paris: Press Universitary de France, 1989.

KATZENBACH, J. R.; SMITH, D. K. A Força e o Poder das Equipes. São Paulo: Makron, 1994.

LEMIEUX, V.; OUIMET, M. Análise estrutural das redes sociais. Lisboa: Instituto Piaget, 2008.

SILVA, R. P. A.; LOPES, B. K.; ANDRADE, L. D. Sociometria nos Jogos Empresariais Simulados: um estudo das interações entre o indivíduo e o grupo. Revista LAGOS, v. 5, n. 1, 2014.

MORENO, J. L. Fundamentos de La sociometria. Buenos Aires: Paidós, 1972.

MOSCOVICl, F. Equipes dão certo: a multiplicação do talento humano. Rio de Janeiro: Jose Olympio, 1994.

MOSCOVICl, S. La Psychanalyse, son image et son public. Paris, Bibliotèque de Psychanalyse, PUF, 1961.

OLIVEIRA, C.; LOPES, H. Coopetição em Redes Interpessoais: Redes são Redes. Rio de Janeiro. Jul.-Ago. p. 508-522, 2014.

OLIVEIRA, N.; SOUZA, D. L.; CASTRO, C. C. Análise sociométrica da rede de relacionamento das bibliotecas que constituem o Consórcio das Universidades Federais do Sul-Sudeste de Minas Gerais. In: CONGRESSO BRASILEIRO DE BIBLIOTECONOMIA E DCOUMENTAÇÃO, 25., São Paulo. Anais... São Paulo, 2013.

PFEIFFER, J. W.; JONES, E. J. Coleção de exercícios estruturados para treinamento e educação. São Paulo: Intercultural. 1980.

ROSAS, A. R.; SAUAIA A. C. A. Jogos de empresas na educação superior no Brasil: perspectivas para 2010. Enfoque Reflexão Contábil, v. 25, n. 2, p. 72-85, 2006.

SARAVALI, E.G. Dificuldades de aprendizagem e interação social: implicações para a docência. Taubaté: Cabral Editora e Livraria Universitária, 2005.

SAUAIA, A. C. A. Gestão Empreendedora em IES's: Aculturamento do Corpo Docente com Jogos de Empresas Revista Eletrônica de Gestão. Picos, v. 1, n. 1, p. 41-58, 2008.

. Satisfação e aprendizagem em jogos de empresas: contribuições para a educação gerencial. Tese (Doutorado em Administração) - Faculdade de Economia, Administração e Contabilidade da Universidade de São Paulo - FEA/USP, São Paulo. 1995.

Perspectivas em Gestão \& Conhecimento, João Pessoa, v. 7, n. 1, p. 153-169, jan./jun. 2017. 
Artigo recebido em 28/03/2017 e aceito para publicação em 05/04/2017 